\title{
The Motivation behind Islamic Terrorism
}

\author{
Youmna Mohammed \\ New York University Abu Dhabi (NYUAD), Abu Dhabi, United Arab Emirates \\ Email: Yem223@nyu.edu
}

How to cite this paper: Mohammed, Y. (2021). The Motivation behind Islamic Terrorism. Open Journal of Political Science, 11, 630-638. https://doi.org/10.4236/ojps.2021.114040

Received: August 16, 2021

Accepted: October 10, 2021

Published: October 13, 2021

Copyright (c) 2021 by author(s) and Scientific Research Publishing Inc. This work is licensed under the Creative Commons Attribution International License (CC BY 4.0).

http://creativecommons.org/licenses/by/4.0/

Open Access

\begin{abstract}
This paper revolves around the concept of Islamic radicalism. Specifically, it focuses on the motivations behind participating in that radicalism, addressing the question "Why do so many Muslim people choose to join ISIS?" It is one thing to commit acts of terrorism, but it is something else entirely to commit that terrorism when you follow a peaceful religion that goes against it; a religion like Islam. Overall, this paper will present a hypothesis related to why many Muslims choose to join ISIS, discuss important theories and concepts related to that hypothesis, and present and analyze relevant literature in order to either prove or disprove the hypothesis.
\end{abstract}

\section{Keywords}

Terrorism, Islamic Terrorism, Psychology, Resentment, Religion, Unfair Treatment, Marginalization, Repression, Muslims, ISIS, Status, Identity, The West, Prejudice, Radicalization, Injustice, Islamic Radicalism, Anger, Revenge

\section{Introduction}

This paper revolves around the motivation behind Islamic radicalism. Specifically, it refers to ISIS as a representation of that radicalism, therefore addressing the question "Why do so many Muslim people choose to join ISIS?" In other words, why would those who identify as Muslim, and who claim to follow the teachings of Islam, dedicate their lives to torturing and killing millions of people around the world? It is one thing to commit acts of terrorism, but it is something else entirely to commit that terrorism when you follow a peaceful religion that goes against it; a religion like Islam. The importance of addressing this question lies, of course, in the fact that it can prevent potential targets from joining ISIS in the long run. This is because once people are made aware of why so many Muslims choose to join ISIS, actions can be taken against this motivation and towards a more peaceful and protective environment around Muslims and other 
potential targets, which would make these targets much harder to reach out to and persuade. Overall, this paper will present a hypothesis related to why many Muslims choose to join ISIS, discuss important theories and concepts related to that hypothesis, and present and analyze relevant literature in order to either prove or disprove the hypothesis.

Before addressing this paper's hypothesis by analyzing relevant literature, it is important to explore the different concepts that form the basis of this paper. Perhaps the most important of these is the concept of Islamic radicalism, also known as Islamic extremism. Islamic radicalism is a movement that aims to violently transform the status quo (unbelief and injustice) into a world of Islamic faith (Iman) and Islamic laws (Sharia) (Hassan, 2013). Specifically, this paper uses ISIS as the main example of Islamic radicalism, so it is important to understand what ISIS is. ISIS, or the Islamic State of Iraq and the Levant, is a terrorist organization that aims to form an Islamic state (known as caliphate) across Syria, Iraq, and beyond (CNN, 2020). Another important concept that this paper revolves around is the concept of resentment. In this paper, resentment will be defined as a feeling of unhappiness or anger about something that one considers to be unfair (Oxford Advanced Learner's Dictionary).

\section{Hypothesis}

In regard to this paper's hypothesis, there is a connection between Islamic radicalism and resentment that this paper aims to address. Specifically, this paper hypothesizes that there is a feeling of resentment (anger towards the west due to unfair treatment) that some Muslims harbor towards the west, and this causes them to join ISIS. The reason this hypothesis is proposed is because resentment is a powerful trigger for violence (Bonn, 2017), and violence forms the basis of organizations like ISIS. More specifically, it has also been proven that resentment, usually as a result of discrimination and other forms of unfair treatment, can be a cause for terrorism (Byman, 1998). If this paper reveals that the hypothesis is true, there are a lot of implications that this can carry. Firstly, knowing that resentment lies behind Muslims joining ISIS is an introduction to the power that resentment can hold and the horrible things that it could lead to. This is because one discovers that a feeling of anger or indignation due to unfair treatment (resentment) can cause thousands of people to join an organization whose objective is mass murder in the name of Islam. Another implication that this hypothesis could carry, if it is true, is that resentment can overpower one's love for family, friends, and religion, because proving the hypothesis true means that Muslims join ISIS because of their resentment and, by joining ISIS, these Muslims also make the decision to abandon their loved ones and their religion. Finally, if the hypothesis is proven true, there is the idea that, if we want to put an end to Islamic terrorism, serious action must be taken against the resentment that causes Muslims to join ISIS in the first place. Once this resentment is reduced, the chances of a Muslim joining ISIS will decrease. In short, what this 
paper hypothesizes is that resentment can cause many Muslims to join ISIS, and therefore answers the question "Why do so many Muslim people choose to join ISIS?"

In regard to the theories that form the hypothesis, there is one theory that is perhaps the most important: resentment can lead to terrorism. This is because the hypothesis states that Muslims feel resentment and joining ISIS (as a result of that resentment) means leading a life of terrorism. Another important theory that the hypothesis involves is that religion can be used as an excuse for terrorism; ISIS commits acts of terrorism in order to build an Islamic state; it uses Islam as an excuse for terrorism and, therefore, the Muslims who choose to join ISIS are also using Islam as an excuse for terrorism. In short, this paper's hypothesis is based on two main theories 1) resentment can lead to terrorism, and 2) religion can be used as an excuse for terrorism.

\section{Literature Review}

"Why Do People Join ISIS? Here's What They Say When You Ask Them" is an article written by Patrick Tucker. In the article, Tucker delves into a report from Lebanon's Quantum Communications researchers who conducted research that studied a sample of 49 fighters in Iraq and Syria (members of ISIS) and collected information about the reasons behind them joining the organization. First, Tucker reveals that the researchers divided the fighters into 9 groups: 1) status seekers (those who were interested in improving their social status); 2) identity-seekers (those who wanted a new identity that ISIS provided for them); 3) revenge seekers (due to considering themselves to be part of a group that is being repressed by the west or another group); 4) redemption seekers (those who believed that joining ISIS would remove all their past sins); 5) responsibility seekers (those who joined because of the need for financial/material support); 6) thrill seekers (those who joined for the thrill or adventure); 7) ideology seekers (joined to impose their view of Islam on others); 8) justice seekers (join as a response to what they see as injustice occurring in the world); and 9) death seekers (have suffered trauma and believe that death is the only way out with the reputation of a martyr rather than just someone who committed suicide). More specifically, the following are the reasons for joining ISIS that the fighters mentioned: defending Sunnis, jihad, the radical environment, the feeling of Muslim belonging, the war in Syria, money, and rejection of Western culture, the most common in the study being defending Sunnis and the least common being rejection of Western culture. However, these motivators varied by the fighters' countries of origin. For instance, those who joined from the United States or another Western region tended to report identity crises, rejection of Western culture, or a desire for recognition, while those who joined from Muslim backgrounds tended to report the war in Syria as their main motivation. Those coming from Syria and Iraq, specifically, tended to be more motivated by money and status (Tucker, 2021). What most connects Tucker's findings to this paper's hypothe- 
sis, however, is his mention of revenge as a motivation behind Islamic terrorism, because revenge is something that is very closely connected to resentment and could even have a cause-and-effect relationship with it, as will be explained later. It seems, therefore, that Tucker's idea is connected to this paper's hypothesis; ideas of injustice, anger, and how the two could relate to Islamic radicalism are discussed.

Similar to Tucker's article, “Talking to Terrorists: What Drives Young People to Become Foreign Fighters for ISIS and Other Terrorist Groups and What Can Be Done in Response" by Anne Speckhard explores how injustice by the west on Muslims and a desire to belong can motivate Muslims to join ISIS, but Speckhard also discusses different motivators such as a desire for status and rejection of Western culture. Firstly, Speckhard discusses the four different elements of what she calls "the terrorist cocktail", or the different things that compose terrorism: 1) a political aim that is seen only through the lens of violence (a political group willing to use only violence); 2) an ideology within that group which justifies the use of violence because of the importance of its political aim; 3) the presence of social support within an individual's community; and 4) an individual's motivations and vulnerabilities that are exposed to the group, as well as the group's ideology and social support. Secondly, when it comes to the different motivations for joining ISIS, Speckhard found through her research that the primary reasons for being drawn to terrorist groups such as ISIS are revenge and trauma that results from the violence that they have witnessed or experienced themselves. Other motivators include discrimination, marginalization, a desire for adventure, purpose, personal significance, and the desire to belong. Going back to the idea of injustice from the west, however, Speckhard discusses a similar motivation to that which Tucker highlights: anger. Specifically, Speckhard argues that Muslims feel anger towards the west due to injustices and foreign policy which causes targets to be vulnerable to the exaggerated stories told by ISIS about the west. Therefore, like Tucker's findings, Speckhard's findings appear to connect to this paper's hypothesis.

Like both Tucker and Speckhard's articles, "Why join ISIS? The Causes of Terrorism from the Muslim Youth Perspective" by Zara Akbar is a paper that explores themes of injustice by the west on Muslims, but there are some variations such as the role of childhood abuse and hostility towards one's parents in motivating Muslims to join ISIS, both of which Tucker and Speckhard do not explore. Nevertheless, when it comes to the theme of injustice by the west, Akbar explains how Muslim youth's resentment due to injustices towards Muslims around the world, as well as the misinterpretation of Islam in the media, can cause Muslim youth to join terrorist organizations like ISIS. For instance, Akbar states that, in regard to British Muslims, the resentment that they harbor towards biased media representations of Islam can push some of them to radicalism or terrorism. Specifically, Akbar also states how placing the entire Muslim community under the single umbrella of terrorism and, as a result, viewing each 
one of them as a potential terrorist or suspect can actually result in some of these Muslims becoming real terrorists. Treating all Muslims as potential terrorists, therefore, can actually result in what these prejudiced people fear: Islamic terrorism. Akbar, therefore, discusses ideas like resentment, anger, and injustice, all of which are themes that the hypothesis revolves around. Other motivations for joining terrorist groups like ISIS include: 1) the desire for a new identity due to not belonging in western society, which could result from a lack of Muslim integration in these communities; 2) childhood abuse/trauma which can make Muslim youth susceptible to radicalization by ISIS; and 3) hostility that some Muslim youth feel towards their parents which could also be a motivation for joining ISIS.

Similar to Speckhard, Tucker, and Akbar, "Why People Join ISIS" by Andrés Ortega explores how anger due to injustices by the west can cause Muslims to join ISIS, but she explores other motivators such as frustration, adventure, money, friends, and sexual relations. In regard to frustration, Ortega discusses how many Muslims feel marginalized due to not belonging to either their Arab community or the western country in which they might be living, and it is this marginalization that results in the anger and vengeance that are very often motivators for joining ISIS. Adventure, or some sort of thrill, is also a common motivation for joining a terrorist group like ISIS. When it comes to money, what ISIS pays is often a good enough motivation for joining, especially for those who are seeking financial stability. ISIS is also an organization where a Muslim might find many of his/her friends, so a desire to remain with friends can also be a motivation. Finally, the desire for marriage or sexual relations motivates many Muslim youth to join ISIS, which promises to provide them with women if they agree to recruitment. There is also the idea that joining ISIS is some sort of sacrifice for the greater good; Ortega quotes an ISIS fighter who says, "Better an end to the suffering inflicted by the status quo, with the hope of something better, whatever suffering and horror it takes.” (Ortega et al., 2016). The most important part of Ortega's findings in regard to the hypothesis, however, is the idea that many Muslims feel anger due to injustices inflicted by the west. This anger, how it results from injustice, and its potential connection to Islamic radicalism are ideas that connect Ortega's findings to this paper's hypothesis.

Like the previous authors' papers, "Foreign Fighters in Iraq and Syria-Why So Many?" by Abdul Basit is an article that explores themes like resentment and identity, but also delves into different motivations such as clashes between the two Islamic sects and ISIS's convincing tactics. The first reason as to why so many Muslims have joined ISIS, according to Basit, is they believe in the Islamic idea that, in Syria, the "final battle of all time between good and evil forces" will occur. This, in turn, attracts Muslims to Syria and, in turn, ISIS. The second motivation behind many Muslims joining ISIS is the desire to defend what they call the "Islamic State", which mainly results from the injustices and misrepresentation of Islam that the west spreads. This, in turn, causes feelings of sadness and 
anger in Muslims living in western communities, as well as a desire for a sense of identity, which many of them believe they can find in ISIS. Another reason behind a lot of Muslims joining is connected to the two Islamic sects: Sunni and Shia. Particularly, the conflicts between them have caused Sunni Muslims, for instance, to join ISIS in an attempt to fight against the Shia regimes of Syria and Iraq. Many Shia Muslims, on the other hand, have directed their followers to go to Iraq and Syria and protect their holy relics and shrines from Sunnis. These trips to Syria and Iraq by both Sunni and Shia Muslims could then lead to them being radicalized and becoming members of ISIS. Other reasons behind many Muslims joining ISIS include the organization's active engagement with social media and online platforms that have resulted in the radicalization of many Muslims, their welcoming attitude, and its tactics, which are mainly connected to their wealth and military strength (Basit, 2014). It seems that a desire for identity and injustice by the west on Muslims connects Basit's findings to Ortega, Speckhard, Tucker, and Akbar's findings, and therefore connects them to the hypothesis of this paper. In other words, Basit discusses themes of injustice anger, and how the two relate to Islamic radicalism. This exploration is significant when addressing this paper's hypothesis, as will be revealed later. In short, all five of the authors discuss themes and ideas that connect to this paper's hypothesis; anger, injustice, and resentment are explored by each of the authors and, as a result, allow for a logical discussion around this paper's hypothesis and a reliable decision regarding its validity.

\section{Discussion}

After stating the hypothesis and exploring the different concepts and theories that form it, this paper addresses that hypothesis by delving into the connections discussed in the literature above in order to reveal whether or not it is valid. Firstly, this paper discusses Patrick Tucker's findings in the article "Why Do People Join ISIS? Here's What They Say When You Ask Them". In the article, Tucker mentions revenge as a motivation for joining ISIS, and because revenge is something that can occur due to resentment (GoodTherapy Blog, 2019), Tucker's findings show that resentment can cause Muslims to join ISIS, supporting this paper's hypothesis. In regard to Anne Speckhard's article, “Talking to Terrorists: What Drives Young People to Become Foreign Fighters for ISIS and Other Terrorist Groups and What Can Be Done in Response" (Speckhard, 2015), her findings can also be discussed in order to address this paper's hypothesis. According to Speckhard, anger towards the west due to injustice/unfair treatment towards Muslims can cause them to join ISIS. Since anger due to unfair treatment is the definition of resentment, Speckhard's article reveals that resentment can lead Muslims to join ISIS.

Zara Akbar's article, "Why join ISIS? The Causes of Terrorism from the Muslim Youth Perspective", also proves the hypothesis of this paper. Akbar focuses on resentment as the main motivation behind Muslims joining ISIS. Specifically, 
she states that, when it comes to British Muslim youth, some of them harbor resentment towards the west due to media misinterpretations of Islam, and also because of the generalization (viewing all Muslims as terrorists) that members of the west implement when interacting with Muslims. This feeling of resentment, according to Akbar, can cause Muslim youth to join terrorist groups like ISIS. Ortega's blog, "Why People Join ISIS", explains that anger is a strong motivation behind Muslims joining ISIS, and that it results from marginalization, a form of unfair treatment, that is occurring to many Muslims in western countries. In other words, Ortega argues that anger due to marginalization, or resentment due to unfair treatment, causes many Muslims to join ISIS. Ortega's findings, therefore, support this paper's hypothesis. Finally, "Foreign Fighters in Iraq and Syria-Why So Many?" by Abdul Basit discusses slightly different motivations behind joining ISIS, but there is some key information in the article that can be used to support this paper's hypothesis. In Basit's article, there is one motivation that most closely resembles this paper's hypothesis: the anger that many Muslims feel due to the injustices inflicted by the West on Muslims (resentment). According to Basit, this resentment causes many Muslims to want to defend the so-called "Islamic State", and as this is what ISIS claims to represent, these Muslims choose to join ISIS in order to fulfill that desire. Basit's argument, therefore, directly mirrors this paper's hypothesis because it reveals that Muslims harbor a feeling of resentment due to unfair treatment, and it is this resentment that causes many of them to join ISIS.

\section{Conclusion}

In conclusion, it seems that all of the literature discussed in this paper conveys that the hypothesis is true; there is indeed a feeling of resentment that many Muslims harbor due to injustice/unfair treatment by the west on Muslims, and this feeling of resentment can cause them to join ISIS. However, although one can acknowledge that resentment is a motivation behind joining ISIS, this does not mean that all of the other motivations are insignificant. Although the authors mentioned above explore the role of resentment as a motivation for joining ISIS, they also explore other common motivators such as a desire for identity, thrill/adventure, sexual relations, friendship, the need for responsibility, trauma, childhood abuse, and so on. These different motivators are equally important when discussing the topic of Islamic radicalization because they all are capable of causing so much damage and destruction in the world. Nevertheless, now that we know that resentment motivates many Muslims to join ISIS, what are some implications of this, and what possible solutions can be devised after acknowledging these implications? Firstly, as mentioned at the beginning of this paper, knowing that resentment motivates many Muslims to join ISIS has three main implications: 1) a feeling of anger can have so much power in terms of being capable of causing so much damage in the world; 2) resentment can overpower one's love for family and friends (because it can cause people to join ISIS and 
therefore leave their family/friends); and 3) in order to reduce Islamic terrorism, an action must be taken against the resentment that causes many Muslims to engage in that terrorism. Secondly, these implications can be used to devise some possible solutions/ways to decrease the number of Muslims who choose to join ISIS. Because it is now implied that resentment can hold so much power, more efforts should be put into understanding why that is. In other words, it is important to explore why is resentment so powerful as a motivation behind violence and, as a result, Islamic terrorism. Psychologists could look into how resentment controls behavior and, as a result, develop ways to help people cope with that resentment in a way that doesn't give it so much power. Also, after knowing that resentment can overpower one's love for family and friends, it is important to understand the isolative power of organizations like ISIS, because it is this isolative power that separates Muslims from their friends and family and, as a result, overpowers their love for them. Finally, knowing that serious action must be taken against resentment tells us that we should put an effort into changing the way the west views Muslims and the Muslim world, which could then reduce the injustice and unfair treatment from the west that causes Muslims to harbor resentment in the first place. These three solutions, if applied correctly, can make a very significant difference in the spread of Islamic radicalism today, because they tackle something that can cause thousands of Muslims around the world to become terrorists: resentment.

\section{Conflicts of Interest}

The authors declare no conflicts of interest regarding the publication of this paper.

\section{References}

Bonn, S. A. (2017). Fear-Based Anger Is the Primary Motive for Violence. Psychology Today, Sussex Publishers.

https://www.psychologytoday.com/us/blog/wicked-deeds/201707/fear-based-anger-is-t he-primary-motive-violence

GoodTherapy Blog (2019). Resentment. https://www.goodtherapy.org/blog/psychpedia/resentment

Oxford Advanced Learner's Dictionary (n.d.). Resentment. Resentment Noun-Definition, Pictures, Pronunciation and Usage Notes. Oxford Advanced Learner's Dictionary at Oxford Learners Dictionaries.com. https://www.oxfordlearnersdictionaries.com/definition/english/resentment

Speckhard, A. (2015, July 16). Talking to Terrorists: What Drives Young People to Become Foreign Fighters for ISIS and Other Terrorist Groups and What Can Be Done in Response. http://f3magazine.unicri.it/?p=1080

Basit, A. (2014). Foreign Fighters in Iraq and Syria-Why So Many? Counter Terrorist Trends and Analyses, 6, 4-8. https://www.jstor.org/stable/26351282?seq=4\#metadata_info_tab_contents

Hassan, G. S. (2013). Radical Islam/Islamic Radicalism: Towards a Theoretical Framing. Researchgate.net, Jan. 2013. 
https://www.researchgate.net/publication/266030514_Radical_Islam_Islamic_Radicalis m_Towards_a_Theoretical_Framing

Tucker, P. (2021). Why Do People Join ISIS? Here's What They Say When You Ask Them. Defense One, 11 Apr. 2021.

https://www.defenseone.com/threats/2015/12/why-do-people-join-isis-heres-what-the y-say-when-you-ask-them/124295

Byman, D. (1998). The Logic of Ethnic Terrorism. Taylor \& Francis, 21, 149-169.

CNN (2020, Sept. 6). ISIS Fast Facts. CNN, Cable News Network.

Ortega, A. et al. (2016). Why People Join ISIS. Elcano Blog, 17 May 2016.

https://blog.realinstitutoelcano.org/en/why-people-join-isis 